\title{
THE INVENTION OF CANDIDATE COMPOUNDS FROM STRYCHNINE BUSH, PINEAPPLE AND GINGER AS THE MAIN PROTEASE RECEPTOR INHIBITOR OF COVID-19 VIRUS
}

\author{
Novi Yantih $^{1 *(i)}$, Linda Erlina ${ }^{2}$, Esti Mulatsari ${ }^{1}$, Wahono Sumaryono ${ }^{1}$
}

${ }^{1}$ Faculty of Pharmacy, Universitas Pancasila, Jakarta, Indonesia

${ }^{2}$ Faculty of Medicine, Universitas Indonesia, Jakarta, Indonesia

Received - October 10, 2020; Revision - October 24, 2020; Accepted - October 28, 2020

Available Online October 31, 2020

DOI: http://dx.doi.org/10.18006/2020.8(Spl-1-SARS-CoV-2).S202.S209

KEYWORDS
Strychnine bush
Pineapple
Ginger
Mpro SARS-CoV-2
Inhibitor

\begin{abstract}
The emerging coronavirus, Covid-19, has become a worldwide pandemic. The existence of the Covid-19 virus pandemic in the world demands the need to identify and characterize new drug candidates to address the health problem caused by the Covid-19 virus. This study aims to find candidate compounds from strychnine bush (Strychnos lucida), pineapple (Ananas comosus), and ginger (Zingiber officinale) acting as the Mpro receptor inhibitor on Covid-19 virus based on docking modeling. The docking process is carried out using a protein with the pdb code 6LU7, a crystal main protein protease (Mpro) of the Covid-19 which binds to the N3 molecule as an inhibitor based on computational tests. The docking process is conducted using N3 comparison, favipiravir, active metabolite remdesivir, and hydroxychloroquine. The docking result shows that the compounds, ananas 26, zingiberenol, and zingiberol have lower docking energy compared to native ligand (N3), favipiravir, active metabolite remdesivir, and hydroxychloroquine. Ananas 26 compound has the most hydrogen bonds with the Mpro active amino acid residue of the Covid-19 virus, namely: HIS163, ASN142, ASP187, TYR54, and HIS41. This makes Ananas 26 more stable in binding pocket enzymes and more effective in inhibiting enzyme performance than other compounds and positive controls. Potential candidate compounds as SARS-CoV-2 Main Protease inhibitors, ananas 26 from pineapple and zingiberenol as well as zingiberol from ginger, can then undergo potential inhibitor tests by in vitro and in vivo methods on SARS-CoV-2.
\end{abstract}

* Corresponding author

E-mail: yantih.novi@univpancasila.ac.id (Novi Yantih)

Peer review under responsibility of Journal of Experimental Biology and Agricultural Sciences.

Production and Hosting by Horizon Publisher India [HPI] (http://www.horizonpublisherindia.in/).

All rights reserved.
All the articles published by Journal of Experimental Biology and Agricultural Sciences are licensed under a Creative Commons Attribution-NonCommercial 4.0 International License Based on a work at www.jebas.org.

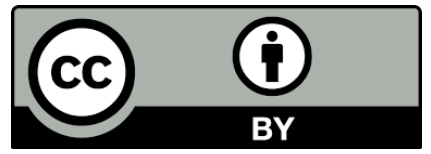




\section{Introduction}

The emergence of coronavirus, SARS-CoV-2 has caused a worldwide pandemic known as coronavirus disease 2019 (COVID19). WHO states permanently that SARS-CoV-2 is the cause of COVID-2019 (Ji et al., 2020). SARS-CoV-2 is a single stranded positive and non-segmented RNA virus. Coronaviruses are included in the order of Nidovirales, Coronaviridae family, and Orthocoronavirinae sub-family, which are divided into groups (genera) $\alpha, \beta, \gamma$, and $\delta$ according to its serotypic and genomic characteristics. Coronavirus is included in the Coronavirus genus of the Coronaviridae family. The virus is named after the protrusion of the wreath in its veil. The coronavirus has sheaths that wrap around the RNA genome, and virion (the whole virus) are round or oval, often polymorphic, with a diameter of 80 to 180nm (Zhou, 2020; Gui et al., 2020). This virus is responsible for the pneumonia virus outbreak that began in December 2019 in Wuhan (Xu et al., 2020).

One of the best targets for designing drugs against SARS-CoV-2 is the main protease section (Mpro which is also often referred to as 3CLPro). Similar to papain-like protease, this enzyme plays an important role in processing the polyprotein translated from RNA virus. The main protease works not less than 11 cleavage sites on polyprotein $1 \mathrm{ab}$ (1ab replicase $\sim 790 \mathrm{kDa}$ ) so that the inhibition of this enzyme's activities will hinder the replication of SARS-CoV-2 (Anand et al., 2003; Hilgenfeld, 2014).

The occurrence of the Covid-19 virus pandemic in the world demands the need to identify and characterize new drug candidates to address health problems caused by the virus. In this context, natural products have emerged as important antiviral agents in recent years (Lin et al., 2014; Martinez et al., 2015).

This study aims to find candidate compounds from Strychnine Bush (Strychnos lucida), pineapple (Ananas comosus), and ginger (Zingiber officinale) acting as the main protease (Mpro) receptor inhibitor on Covid-19 virus based on docking modeling. Docking is one of the computational approach that describes the protein and the ligand as complementary surfaces. This method required the protein structure and ligand conformation that simulated in docking program that produces the docking score represented by binding affinity value as output that describes the binding energy of ligand protein complex dan $\mathrm{Ki}$ that describes the stability of ligand-protein complex (Ballante, 2018). The docking process is carried out using a protein with the pdb code 6LU7, a crystal main protein protease (Mpro) of the Covid-19 which binds to the N3 molecule as an inhibitor based on computational tests. Mpro is the most important part of the $\mathrm{CoV}$ enzyme, which plays a role in mediating viral replication and transcription, Its had an active site that consists of active amino acid, Cys-His catalytic dyads (Cys143 and His-41) which exist between the domains I and II of proteins, that playing an important role as catalytic in proteolytic activity. It making the Mpro is the right target for the development of drugs that inhibit viral development (Anand, 2002; Yang et al, 2003; Jin et al., 2020).

The docking process is conducted using N3 comparison, favipiravir (Cai et al., 2020), remdesivir and active metabolites remdesivir (Eastmant et al., 2020), as well as hydroxychloroquine (Gautret et al., 2020), as an effort to predict the activity of compounds contained in strychnine bush, pineapple, and ginger as main protease receptor inhibitors (Mpro). Strychine bush, pineapple, and ginger contain compounds that have been reported in previous studies that have antiviral activity. Pineapple has tested in vitro can inhibit and prevent the growth of viruses in the blood of patients infected with HIV, Hepatitis C, and HPV viruses. Ginger has been tested to have inhibitory activity against the human respiratory syncytial virus (HRSV) (Chang et al., 2013).

\section{Materials and Methods}

\subsection{Materials}

The 3D structure of SARS-CoV-2 Mpro is acquired from the Protein Data Bank (PDB) with a code, PDB 6LU7 (rcsb.org, 2020). This protein structure has a resolution of $2.16 \AA$, with a sequence length of 306 amino acid without mutation, R-Value Work of 0.202 and RValue Observed of 0.204 . It is identified within the structure of 6LU7, native ligand code N3 (N-[(5-Methylisoxazol-3-Yl) Carbonyl] Alanyl-L-Valyl-N 1 -((1r,2z)-4-(Benzyloxy)-4-Oxo-1$\{[(3 r)-2-O x o p y r r o l i d i n-3-Y l] M e t h y l\} B u t-2-E n y l)-L \quad$ Leucinamide) which is a peptide in chain $\mathrm{C}$. The involved ligands include native ligand (N3) for method validation redocking process, favipiravir (Cai et al., 2020), remdesivir (Eastman et al., 2020), active metabolites remdesivir (Eastman et al., 2020) and hydroxychloroquine (Gautret et al., 2020) as positive controls; 2-methoxy-4-methylphenol; 3ethoxyacetophenone; 2,5-dimethoxybenzyl alcohol; 2,6dimethoxyphenol; and 2,6-Dimethyl-4-nitrophenol, the compounds of strychnine bush (Novian et al., 2019); Ananas 17; Ananas 19; Ananas 21; Ananas 22; Ananas 23; Ananas 26; glutamyl sinapyl cysteine; S-sinapyl glutathione; sinapyl cysteine and bromelain the compounds of pineapple (Ma et al., 2007) and citronellol; farnesol; zingiberene; zingiberenoland zingiberol the compounds of ginger (Liu et al., 2019). All the ligands in the picture use Marvin Sketch's application optimized to 3D in .pdb file type.

\subsection{Apparatus}

The preparation process of ligand and receptor, method validation, docking and visualization of amino acid interactions is done using MacBook Air with MacOS Mojave version 10.14.6, 1.8 GHz Intel Core i5 processor, 8GB memory $1600 \mathrm{MHz}$ DDR3, 8GB graphics $1600 \mathrm{MHz}$ DDR3. 
The software used in drawing ligand structures is Marvin Sketch (Csizmadia et al., 2019). The docking process is done using AutoDock4 (Morris et al., 2009). The docking results are visualized using LigPlot (for 2D interactions) (Laskowski \& Swindells 2011) and 3D visualization is using Ligand Scout 4.3 (Wolber \& Langer, 2005).

\subsection{Procedure}

\subsubsection{Preparation of receptor and ligand structures}

The receptor structure of the SARS-CoV-2 Main Protease, code 6LU7 undergoes geometric optimization, removal of water molecules, the addition of hydrogen atoms, addition of Gasteiger charges using Autodock4 stored in the.pdbqt file type. Positive control compound 1 (PC1) (favipiravir) (Cai et al., 2020); PC2 (active metabolites remdesivir) (Eastman et al., 2020); PC3 (remdesivir) (Eastman et al., 2020), PC4 (hydroxychloroquine) (Gautret et al., 2020); pineapple compounds (Ananas 17; Ananas 19; Ananas 21; Ananas 22; Ananas 23; Ananas 26; glutamyl sinapyl cysteine; S-sinapyl glutathione; sinapyl cysteine and bromelain) (Ma et al., 2007); strychnine bush compounds (2-methoxy-4-methylphenol; 3-ethoxyacetophenone; 2,5dimethoxybenzyl alcohol; 2,6-dimethoxyphenol; and 2,6-Dimethyl-4nitrophenol) (Novian et al., 2019) and ginger compounds (citronellol; farnesol; zingiberene; zingiberenol and zingiberol) (Liu et al., 2019) are drawn and 3D-optimized in Marvin Sketch, saved in the form of .pdb and .pdbqt files.

\subsubsection{Docking method validation}

The validation of the docking method is done by redocking the native ligand (N3) optimized with 3 grid box sizes, 40x54x40, $50 \times 64 \times 50$ and $60 \times 74 \times 60$ with grid center coordinates $X:-9.768$; $\mathrm{Y}: 11,424 ; \mathrm{Z}: 68,935$. The redocking process is run using Lamarckian GA parameters with 100 times GA run; spacing 0.375 $\AA$ and also the evaluation of RSMD values.

\subsubsection{Analysis of docking results and visualization of receptor- ligand interactions}

The process of grid optimization is done in Autogrid4 using the optimum gridbox which is $50 \times 64 \times 50$, grid center $\mathrm{X}$ : -9.768 ; $\mathrm{Y}$ : 11,424; Z: 68,935 and spacing $0.375 \AA$. The docking process is run with the Lamarckian GA Autodock4 parameter (10 times of GA run) with the output file. dlg. The value of binding affinity, ki, and the interaction of amino acid binding site residues with ligands are analyzed in AutoDock4 (3D), LigPlot (2D) and 3D-visualized in LigandScout 4.3.

\section{Results and Discussion}

The structure of SARS-CoV-2 Main Protease, PDB ID: 6LU7 has a native ligand in the form of peptide compound code N3. Mpro in
$\mathrm{CoV}$ is very important for the proteolytic maturation of viruses, this protein seems to be a suitable target in drug development that can prevent the spread of infection by inhibiting the division of the polyproteins of the virus. Based on research by Jin et al. (2020), it is witnessed that compound $\mathrm{N} 3$ is a potential compound as a SARS$\mathrm{CoV}-2$ inhibitor with an $\mathrm{EC}_{50}$ value of $16.77 \mathrm{uM}$. N3 can occupy the SARS-CoV-2 binding pocket with low energy. The native ligand compound (N3) is separated from the SARS-CoV-2 main protease protein (PDB ID: 6LU7) (Jin et al., 2020) and the torque is optimized and then stored in a .pdbqt file type which is used for the redocking process. Positive control (PC) compound PC1 (favipiravir) (Cai et al., 2020); PC2 (active metabolite remdesivir) (Eastman et al., 2020); PC3 (remdesivir) (Eastman et al., 2020), PC4 (hydroxychloroquine) (Gautret et al., 2020); pineapple compounds (Ananas 17; Ananas 19; Ananas 21; Ananas 22; Ananas 23; Ananas 26; Glutamyl sinapyl cysteine; S-sinapyl glutathione; Sinapyl cysteine and bromelain) (Liu et al., 2019); strychnine bush compounds (2-methoxy-4methylphenol; 3-ethoxyacetophenone; 2,5-dimethoxybenzyl alcohol; 2,6-dimethoxyphenol; and 2,6-Dimethyl-4-nitrophenol) and ginger compounds (Citronellol; Farnesol; zingiberene; zingiberenol and zingiberol)(Liu et al., 2019) are drawn and 3D-optimizedin Marvin Sketch, saved in the form of .pdb and .pdbqt files type.

The validation process is done by determining the grid center and grid box as the binding position of the test ligand at the receptor binding site. Validation is done by redocking the Mpro protein without ligand with the native ligand under the variations of grid box dimension. The results and visualization of the interaction validation of the molecular docking method is presented in Table 1 and Figure 1.

Table 1 Docking Energy and Ki values on several grid box dimensions (*grid center X: -9.768; Y: 11.424; Z: 68.935)

\begin{tabular}{|lccc|}
\hline (*) Grid Box & $40 \times 54 \times 40$ & $50 \times 64 \times 50$ & $60 \times 74 \times 60$ \\
\hline Docking Energy & $\begin{array}{c}-6.98 \\
\mathrm{kcal.mol}\end{array}$ & $\begin{array}{c}-7.34 \\
\mathrm{kcal} . \mathrm{mol}^{-1}\end{array}$ & $\begin{array}{c}-6.19 \\
\mathrm{kcal}^{-1} \mathrm{~mol}^{-1}\end{array}$ \\
\hline $\mathrm{Ki}$ & $7.65 \mathrm{uM}$ & $4.16 \mathrm{uM}$ & $28.86 \mathrm{uM}$ \\
\hline RMSD & $4.62 \AA$ & $3.15 \AA$ & $4.94 \AA$ \\
\hline
\end{tabular}

The result of the docking method validation shows that the docking method with the smallest RMSD value on the grid box with a dimension of $50 \times 64 \times 50$, the energy docking value of -7.34 kcal.mol ${ }^{-1}$, and inhibition constant of $4.16 \mu \mathrm{M}$ and RMSD $3.15 \AA$. The smaller the obtained RMSD value, the closer the pose of docking result ligand to native ligand confirmation showing that the method is confirmed to be more accurate (Kirchmair et al., 2008). The hydrogen bond formed between the ligand, resulting from redocking, and the active amino acid Mpro of Covid-19 virus have similarities with the hydrogen bond formed by the native ligand, namely on the active amino acids GLY143, HIS163, GLU166, THR190, and HIS164. 


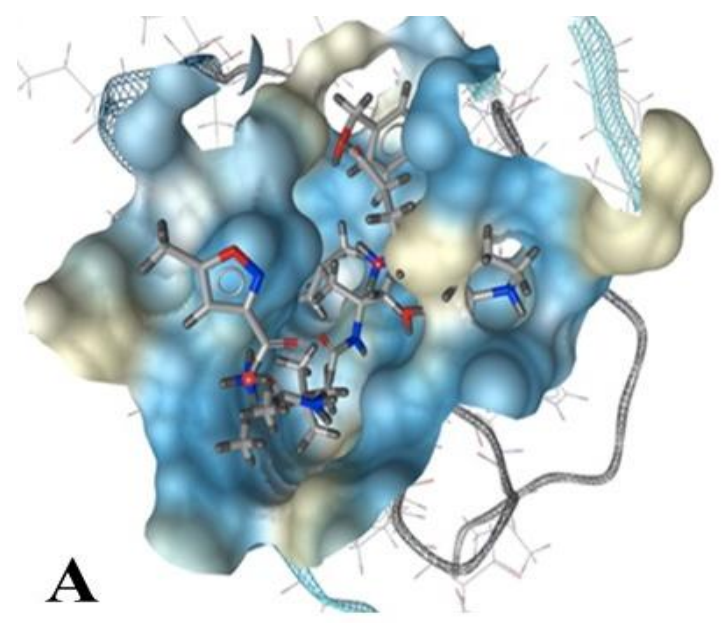

The docking process of compounds contained in strychnine bush, pineapple and ginger are carried out on the active site of Covid-19 virus Mpro with the validated coordinates and grid box dimension. The test compounds are previously prepared and geometrically optimized to determine the ligand conformation with the lowest/stable energy. Docking results obtained are in the forms of docking energy data, hydrogen bonds and inhibition constants. The data on the docking results of the test compounds are presented in Table 2.

The positive control compound 2, redemsivir (PC2) used is its active metabolite because redemsivir itself is a prodrug, that it has entered the body's system it will be degraded into active metabolite compounds (Eastman et al., 2020). The docking results show that compared to the native ligand compound (N3) and the four positive control compounds (favipiravir, active metabolites redemsivir, remdesivir, and hydroxychloroquine), ananas 26 and zingiberenol compounds have lower docking energy. This indicates that ananas 26 and zingiberenol compounds are predicted to have the ability to inhibit the performance of Covid19 virus Mpro with better effectiveness due to lower inhibitory constant values. Ananas 26 compound from pineapple has the smallest docking energy compared to other compounds. This indicates that the ananas 26 compound is the most stable to bind with active amino acids from protein. A low inhibitory constant value indicates that the ananas 26 compound is more effective in its role of inhibiting the performance of Covid-19 Mpro in the replication process. A low inhibitory constant show that the formed ligand-protein complex is more stable and tends to be irreversible. Meanwhile, ginger rhizome shows that zingiberenol and zingiberol have the lowest docking energy and negative (negative) inhibitory constants compared to other compounds contained in ginger.

The visualization of ligand interaction with the amino acid residues of Covid-19 Mpro (Figure 2) shows that Ananas 26 forms a hydrogen bond with the amino acids HIS163, ASN142, ASP187, TYR54, and HIS41. Zingiberenol forms a hydrogen bond with the amino acid THR190. Zingiberol forms a hydrogen bond with the amino acid GLU166. Favipiravir forms hydrogen bonds with SER144, CYS145, and GLY143. Active metabolite remdesivir forms hydrogen bonds with the amino acids GLN 189 and GLU166, while remdesivir forms hydrogen bonds with amino acids GLN189, THR24, and CYS145. Hydroxychloroquine forms hydrogen bonds with the amino acid GLY143 (Figure 3). Based on these results, ananas 26, zingiberenol, zingiberol, favipiravir and remdesivir interact with important amino acid residues in the binding pocket of the Covid-19 virus Mpro enzyme with varying numbers of hydrogen bonds (Table 3). Mpro in the SARS-CoV-2 virus is responsible for the cell replication process. 


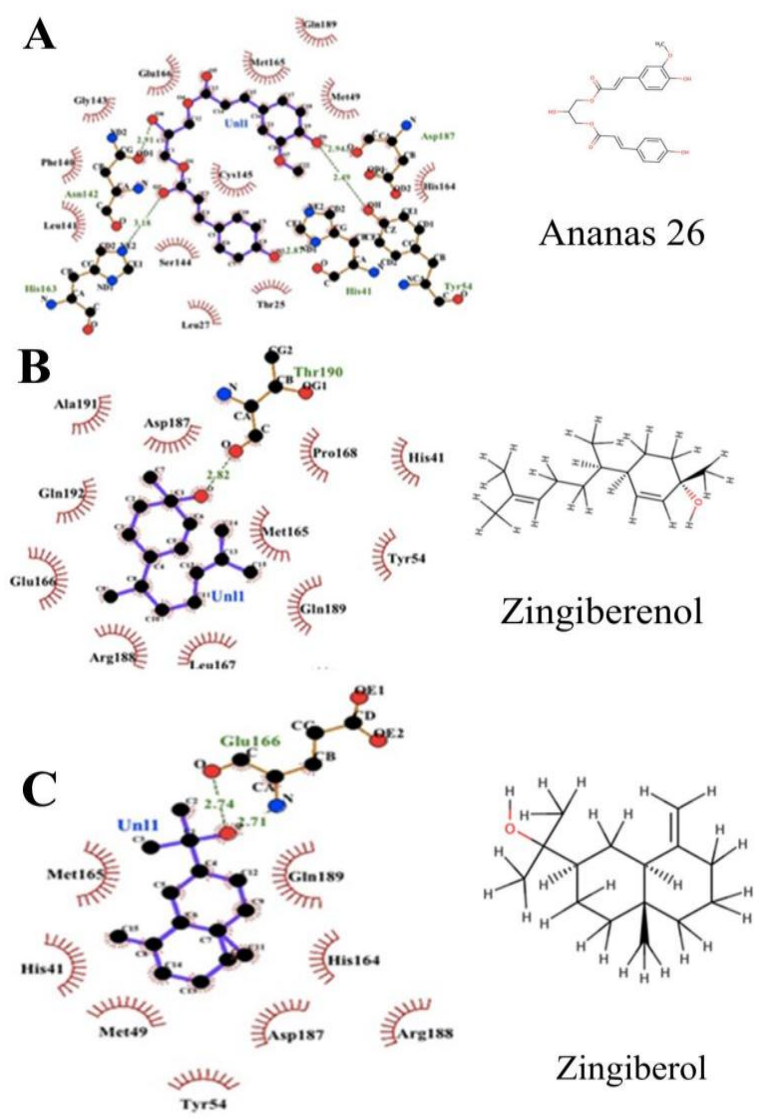

Figure 2 The interaction of A) Ananas 26; B) Zingiberenol; C) Zingiberol with active amino acids of Mpro SARS-CoV-2 virus (Hydrogen Bonds in green dotted line)

The active side of Mpro contains Cys-His catalytic dyads (Cys-143 and His-41) which exist between the domains I and II of proteins, playing an important role as catalytic in proteolytic activity (Anand, 2002; Anand et al., 2003; Yang et al., 2003; Jin et al, 2020). The formation of hydrogen bonds between the O hydroxyl atom in the benzene side chain of the compound ananas 26 with $\mathrm{H}$ $\mathrm{N}$ in the amino acid residue HIS41 is capable of blocking the residual catalytic properties, thereby inhibiting the replication process.

Ananas 26 compound has the most hydrogen bonds with the active amino acid residue of the Covid-19 virus Mpro, this makes Ananas 26 more stable in binding pocket enzymes and more effective in inhibiting enzyme performance than other compounds and positive controls. The hydroxyl groups in the ananas 26, zingiberenol and zingiberol compounds have a very important role in forming hydrogen bonds with active amino acids. Ananas 26, zingiberenol and zingiberol are the potential compound candidates as Covid-19 inhibitors.

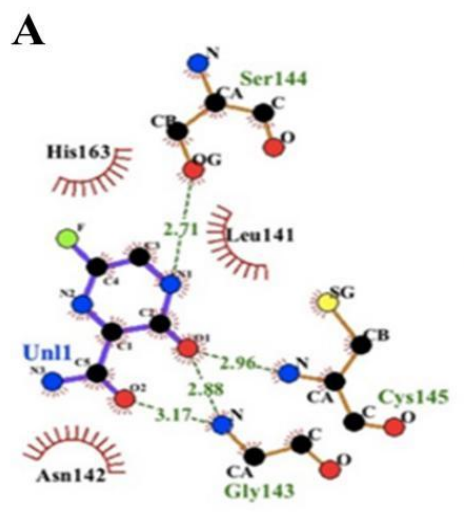<smiles>[2H]c1[nH]c(=O)c(C=O)nc1F</smiles>

Favipiravir
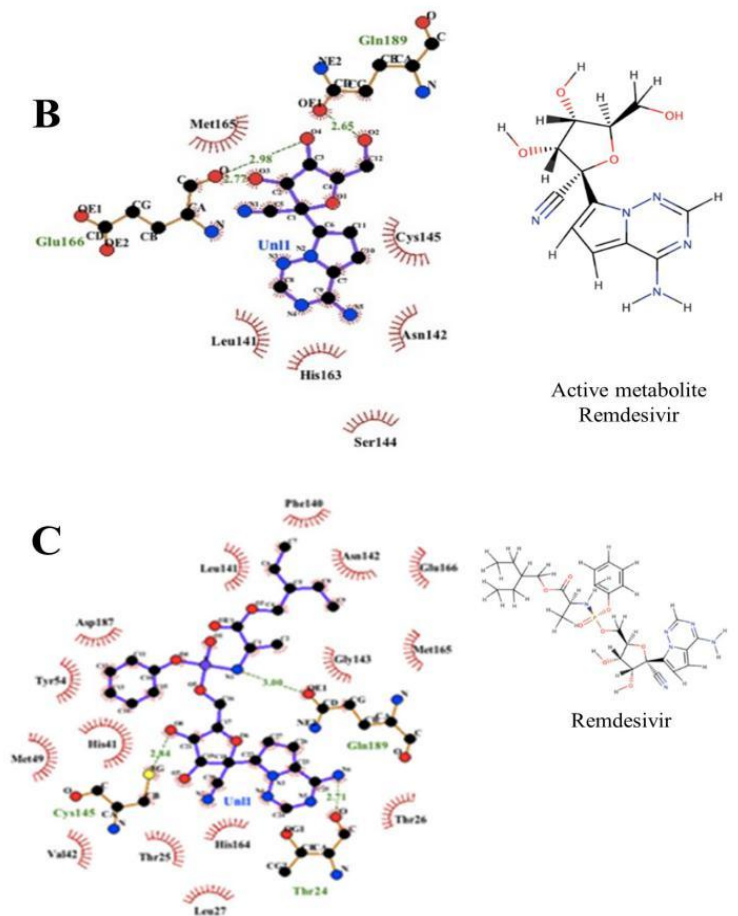

Active metabolite Remdesivir

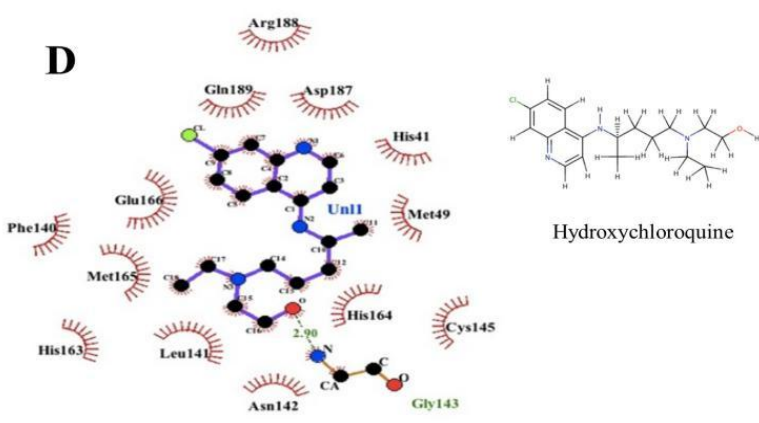

Figure 3 The interaction of A) Favipiravir; B) Active metabolite remdesivir ; C) Remdesivir ; D) Hydroxychloroquine with active amino acids of Mpro SARS-CoV-2 virus (Hydrogen Bonds in green dotted line) 
The Invention of Candidate Compounds from Strychnine Bush, Pineapple and Ginger as Protease Receptor Inhibitor of Covid-19 Virus S207

Table 2 Docking energy and inhibition constant of test compounds from strychnine bush, pineapple, and ginger

\begin{tabular}{|c|c|c|c|c|}
\hline No & Compounds & Origin & Binding affinity $\left(\mathrm{kcal} \mathrm{mol}^{-1}\right)$ & $\mathrm{Ki}(\mathrm{uM})$ \\
\hline PC1 & Favipiravir & - & -4.29 & 711.37 \\
\hline $\mathrm{PC} 2$ & Active metaboliteremdesivir & - & -5.90 & 47.34 \\
\hline PC3 & Remdesivir & - & $-7,32$ & 4.30 \\
\hline PC4 & Hydroxychloroquine & - & -7.03 & 7.06 \\
\hline 1 & 2-methoxy-4-methylphenol & Strychnine Bush & -4.50 & 505.36 \\
\hline 2 & 3-ethoxyacetophenone & Strychnine Bush & -5.40 & 110.57 \\
\hline 3 & 2,5-dimethoxybenzyl alcohol & Strychnine Bush & -4.79 & 309.28 \\
\hline 4 & 2,6-dimethoxyphenol & Strychnine Bush & -4.83 & 286.29 \\
\hline 5 & 2,6-Dimethyl-4-nitrophenol & Strychnine Bush & -5.08 & 190.13 \\
\hline 6 & Ananas 17 & Pineapple & -5.95 & 43.45 \\
\hline 7 & Ananas 19 & Pineapple & -6.15 & 31.13 \\
\hline 8 & Ananas 21 & Pineapple & -6.55 & 15.82 \\
\hline 9 & Ananas 22 & Pineapple & -6.45 & 18.75 \\
\hline 10 & Ananas 23 & Pineapple & -6.54 & 16.08 \\
\hline 11 & Ananas 26 & Pineapple & -7.45 & 3.48 \\
\hline 12 & Citronellol & Ginger & -4.87 & 268.0 \\
\hline 13 & Bromelain & Pineapple & -0.76 & 275340 \\
\hline 14 & Farnesol & Ginger & -6.04 & 37.57 \\
\hline 15 & Glutamyl sinapyl cysteine & Pineapple & -4.43 & 563.41 \\
\hline 16 & S-sinapyl glutathione & Pineapple & -5.24 & 145.1 \\
\hline 17 & Sinapyl cysteine & Pineapple & -5.61 & 76.69 \\
\hline 18 & zingiberene & Ginger & -6.75 & 11.23 \\
\hline 19 & zingiberenol & Ginger & -7.43 & 3.58 \\
\hline 20 & zingiberol & Ginger & -7.31 & 4.38 \\
\hline
\end{tabular}

Table 3 Amino Acid Residues on Test Compounds

\begin{tabular}{|ccc|}
\hline No & Compound & Amino Acid Residues \\
\hline PC1 & Favipiravir & GLY143, CYS145, SER144 \\
\hline PC2 & Active metaboliteremdesivir & GLN 189, GLU166 \\
\hline PC3 & Remdesivir & GLN189, THR24, CYS145 \\
\hline PC4 & Hydroxychloroquine & GLY-143 \\
\hline 1 & Ananas 26 & HIS163, ASN142, ASP187, TYR54, HIS41 \\
\hline 2 & Zingiberenol & GLU166 \\
\hline 3 & Zingiberol & \\
\hline
\end{tabular}

Journal of Experimental Biology and Agricultural Sciences http://www.jebas.org 


\section{Conclusions}

Based on the docking results of 20 compounds derived from pineapple, strychnine bush and ginger, the research obtains three potential compound candidates, one from pineapple (ananas 26) and 2 from ginger (zingiberenol and zingiberol) to be the inhibitor of SARS-CoV-2 Main Protease. Moreover, these three compounds can be further developed through in vitro and in vivo antivirus potential testing for SARS-COV-2.

\section{Author Contributions}

N.Y:Designed the study, responsible for the whole study and creating the report. L.E: Conducted in docking the ligands and receptor. E.M: Selection the receptor in Protein Data Bank, Analyzed the result. W.S: Supervised the process and output study.

\section{Acknowledgement}

The authors are grateful for a research grant from Ministry of Research, Technology and Higher Education of the Republic of Indonesia for founding the research with contract number: 099/LL3/PG/2020

\section{Conflict Of Interest}

Authors would hereby like to declare that there is no conflict of interests that could possibly arise.

\section{References}

Anand K (2002) Structure of coronavirus main proteinase reveals combination of a chymotrypsin fold with an extra alpha-helical domain'. EMBO Journal 21(13):3213-24.

Anand K, Ziebuhr J, Wadhwani P, Mesters JR, Hilgenfeld R (2003) Coronavirus Main Proteinase (3CL ${ }^{\text {pro }}$ ) Structure: Basis for Design of Anti-SARS Drugs'. Science 300 (5626):1763-1767. DOI: $10.1126 /$ science. 1085658 .

Ballante F (2018) Protein-Ligand Docking in Drug Design: Performance Assessment and Binding-Pose Selection. In: Mavromoustakos T, Kellici $\mathrm{T}$ (Eds) Rational Drug Design, Methods in Molecular Biology, Vol 1824. Humana Press, New York, NY. https://doi.org/10.1007/978-1-4939-8630-9_5.

Cai Q, Yang M, Liu D, Chen J, Shu D, Xia J, et al. (2020) Experimental Treatment with Favipiravir for COVID-19: An Open-Label Control Study. Engineering DOI: https://doi.org/10.1016/j.eng.2020.03.007.

Chang JS, Wang KC, Yeh CF, Shieh DE, Chiang LC (2013) Fresh ginger (Zingiber officinale) has anti-viral activity against human respiratory syncytial virus in human respiratory tract cell lines. Journal of Ethnopharmacology 145: 146-151.DOI: https://doi.org/10.1016/j.jep.2012.10.043.

Csizmadia P, Sketch M, Marvin (2019)Molecule Applets for the World Wide Web. In 2019' [cited 2020 May 3]. p. 1775. Available from: www.reprints.net/ecsoc-3.htm.

Eastman RT, Roth JS, Brimacombe KR, Simeonov A, Shen M, Patnaik S, et al. (2020) Remdesivir: A Review of Its Discovery and Development Leading to Emergency Use Authorization for Treatment of COVID-19. ACS Central Science 6(5): 672-683. doi: $10.1021 /$ acscentsci.0c00489.

Gautret P, Lagier JC, Parola P, Hoang VT, Meddeb L, Mailhe M, et al. (2020) Hydroxychloroquine and azithromycin as a treatment of COVID-19: results of an open-label non-randomized clinical trial. International Journal of Antimicrobial Agents 56 (1):105949.

Gui M, Liu X, Guo D, Zhang Z, Yin CC, Chen Y, Xiang Y (2020) Electron microscopy studies of the coronavirus ribonucleoprotein complex. Protein Cell 8: 219-224. https://link.springer.com/article/10.1007/s13238-016-0352-8.

Hilgenfeld R (2014) From SARS to MERS: crystallographic studies on coronaviral proteases enable antiviral drug design. FEBS Journal 281(18):4085-96. http://doi.wiley.com/10.1111/febs.12936.

Ji W, Wang W, Zhao X, Zai J, Li X (2020) Cross-species transmission of the newly identified coronavirus 2019-nCoV. Journal of Medical Virology 92(4):433-40. https://doi.org/10.1002/jmv.25682.

Jin Z, Du X, Xu Y, Deng Y, Liu M, Zhao Y, et al. (2020) Structure of Mpro from COVID-19 virus and discovery of its inhibitors. Nature 582: 289-293: https://doi.org/10.1038/s41586-020-2223-y.

Kirchmair J, Markt P, Distinto S, Wolber G, Langer T (2008) Evaluation of the performance of $3 \mathrm{D}$ virtual screening protocols: RMSD comparisons, enrichment assessments, and decoy selection-What can we learn from earlier mistakes?'. Journal of Computer-Aided Molecular Design 22: 213-228. https://doi.org/10.1007/s10822-007-9163-6.

Laskowski RA, Swindells MB (2011) LigPlot +: Multiple Ligand À Protein Interaction Diagrams for Drug Discovery. Journal of Chemical Information and Modeling 51 (10) 2778-2786. DOI: https://doi.org/10.1021/ci200227u.

Lin LT, Hsu WC, Lin CC (2014) Antiviral Natural Products and Herbal Medicines. Journal of Traditional and Complementary Medicine 4(1) : 24-35. DOI: https://doi.org/10.4103/22254110.124335 . 
Liu Y, Liu J, Zhang Y (2019) Research Progress on Chemical Constituents of Zingiber officinale Roscoe. Biomed Research International Article ID 5370823 | https://doi.org/10.1155/2019/5370823.

Ma C, Xiao S, Li Z, Wang W, Du L (2007) Characterization of active phenolic components in the ethanolic extract of Ananas comosus $\mathrm{L}$. leaves using high-performance liquid chromatography with diode array detection and tandem mass spectrometry. Journal of Chromatography A 1165(1-2):39-44. doi: 10.1016/j.chroma.2007.07.060.

Martinez JP, Sasse F, Brönstrup M, Diez J, Meyerhans A (2015) Antiviral drug discovery: broad-spectrum drugs from nature Natural Product Reports 32(1):29-48. doi: 10.1039/c4np00085d..

Morris GM, Huey R, Lindstrom W, Sanner MF, Belew RK, Goodsell DS, Olson AJ (2009) AutoDock4 and AutoDockTools4: Automated Docking with Selective Receptor Flexibility. Journal of Computational Chemistry 30(16): 2785-91.

Novian DR, Zahrah A, Ikhwani N, Winarso A, Anatomi D, Biokimia F, et al. (2019) Uji farmakodinamik, drug-likeness, farmakokinetik dan interaksi senyawa aktif Strychnine Bush
(Strychnos lucida) sebagai inhibitor Plasmodium falciparum secara in silico. Jurnal Veteriner Nusantara 2(1):70-8.

Wolber G, Langer T (2005) LigandScout: 3-D Pharmacophores Derived from Protein-Bound Ligands and Their Use as Virtual Screening Filters. Journal of Chemical Information and Modeling 45(1):160-169. https://doi.org/10.1021/ci049885e.

Xu X, Chen P, Wang J, Feng J, Zhou H, Li X, et al. (2020) Evolution of the novel coronavirus from the ongoing Wuhan outbreak and modeling of its spike protein for risk of human transmission. Science China Life Sciences 63(3):457-60. https://doi.org/10.1007/s11427-020-1637-5.

Yang H, Yang M, Ding Y, Liu Y, Lou Z, Zhou Z, et al. (2003) The crystal structures of severe acute respiratory syndrome virus main protease and its complex with an inhibitor. Proceedings of the National Academy of Sciences of the United States of America 100(23):13190-13195.

Zhou W (2020) Coronavirus Prevention Handbook. In: Wang Q, Hu K, Zaiqi Zhang NZ (Eds.) Wuhan Center for Disease Control and Prevention; Pp 101. 